\title{
Sex on the Racks: Issues of Data Collection and Access
}

\author{
by Daniel C. Tsang ' \\ Machine-Readable Data Files Librarian \\ Main Library \\ University of California, Irvine \\ California
}

In the midst of the AIDS crisis, researchers seeking accurate empirical data about the prevalence of high-risk sexual behaviors, or the population of homosexuals in the United States, are increasingly frustrated at the lack of reliable and accurate data. Instead, researchers are reaching back some forty years, relying on Kinsey-era non-generalisable data to estimate the number of homosexuals expected to come down with AIDS (Fay et al, $1989,243)$.

This absence of reliable new data (except for a 1970 national study) since Alfred Kinsey's landmark studies of male and female human sexuality in the 1940s and 1950s is due to many factors, including long-standing taboos over certain sexual practices as well as political opposition. Most recently, this led to Congress scuttling, last year, a planned national survey of sexual habits of Americans, after conservative Congressmen, such as California's William E. Dannemeyer (who said the survey was "more apropos for the pages of a pornographic magazine"), mounted a successful campaign to oppose federal funding of a National Opinion Research Center (NORC) national sex survey (Associated Press, 1989; Booth, 1989a, 1989b; Dannemeyer, 1989; Hayden, 1989; “Kinsey 1I," 1989; Peterson, 1989; Specter, 1989, 1990).

On the other hand, the U.S. Census Bureau, in its 1990 decennial census, has been able to gather information on domestic partnerships, so that for the first time in U.S. history, lesbian and gay couples who live with each other are being counted in a national census (Vobejda, 1990). That this unprecedented exercise in data collection will not be $100 \%$ successful is apparent from the concerns some gay activists have voiced about whether they trust the government to maintain confidentiality of the data; the memory of what happened in World War II, with the release of census data to the military regarding the distribution of Japanese Americans, and their subsequent internment, remains too real to many Amcricans.

Despite the national setback regarding a sex survey, the Centers for Disease Control is attempting to gather data at the municipal level; a number of cities have been slated for projects assessing behaviors that are considered high risk for AlDS, although not without having to overcome local opposition from residents who fear a repeat of the Tuskegee Experiment, when the Public Health Service deliberately did not treat hundreds of black men for syphilis (Boffey, 1987; Boodman, 1988a and 1988b).

Ironically while Congress has focused its attention on stopping the national sex survey, it has overlooked the invasion of law enforcement agents into an arena traditionally the domain of social scientists, and allowed the proliferation of sex surveys aimed, not at promoting public health, but at entrapping those suspected of being interested in pornography. Hundreds of Americans have been sent to prison, in part because they filled out a bogus sex survey commissioned, surreptitiously, by U.S. Customs or the U.S. Postal Inspection Service. Our sex police have, in fact, mastered desktop publishing, and sent questionnaires to thousands of Americans, asking about intimate details of their sex lives, including whether they are interested in sex with children or with animals (see Appendix A for an example). Respondents - who may well have been indulging in taboo fantasies - are subsequently sold child pornography published by these law enforcement agencies - and after their homes or businesses are raided, sent to jail for 10 years or more for receiving pornography. The questionnaires they have filled out prevent them from claiming entrapment because their answers on the questionnaires indicate they are predisposed to the crime of receiving pornography (Bull, 1987; Johansen, 1988; Lee, 1987; Stanley, 1988, 1989; Tsang 1987).

It is thus not surprising that, while law enforcement agents can conduct these surveys without any oversight by Congress or by human subjects review boards, independent researchers - not connected to the criminal justice establishment - are finding out that certain sexual practices - such as childhood sexuality - are taboo and cannot be researched without law enforcement involvement. In fact, an increasing number of researchers have themselves been arrested, their research confiscated, their careers destroyed, all because they picked a subject too taboo to research (Sonenschein, 1987). Furthermore, as sexologist John Money has suggested, "The only way a researcher can get Government funding is to be against sex" (Money, 1990).

Sex data collection, therefore, is a highly politicized 
endeavor, especially in the post-Meese Commission era. It raises important ethical issues - not only about the ethics of breaching confidentiality (as in data on sexual partners) - but also the ethics of hiding the true (law enforcement) purpose of a sex survey (Tsang, 1989).

Politics aside, all sexual behavior studies are faced with two major technical difficulties, viz., bias in the selection of subjects and the reliability of the responses (Forman and Chilvers, 1989, 1140). Kinsey and his colleagues did not conduct a national sample, but instead relied on participants on selected campuses and in specific organizations. With homosexual acts still criminalized in half the United States and discrimination against persons with AIDS rampant, respondents may be unlikely to admit to illegal activities or tell the truth (Wolpert, 1989). Further the specter of Big Brother asking these questions and the inability to convince everyone of the confidentiality of one's responses makes the reliability of the data particularly questionable. Missing data will be a common result (Reinisch, 1988). An undercount is also the likely result.

For the data librarian or the data user, this means that one should approach these data with more than the usual skepticism. It may also mean that researchers are less willing to part with these data.

The universe of sharable existing data on human sexual behavior is rather small. First, there is very little tradition among sex researchers (like other researchers) of citing the availability of their data in their research. Although the National Science Foundation has now mandated that grantees deposit or make available their data, this has not caught on in the sex research community. Furthermore, much of what passes for empirical sex research is either of the case study variety, or college sophomores' reports of their sex habits. This type of data may be of less interest to other researchers than something more systematically gathered. With the increase in good AIDS data, however, more interest in sharing data can be expected. If the data is publicly supported, one can well argue that they should not be made inaccessible. Privately supported data will be harder to get, of course; it took almost two decades before a Kinsey Institute study of sexual behavior, conducted by NORC in 1970, was finally released to other researchers, in part because of a dispute over which researcher would be listed as the primary author (Booth, 1988; Reinisch, 1988; Klassen, [988).

In the United States, excluding funding agencies such as the federal government, there are two main sources that collect and distribute datasets that have material relating to this topic.

The Inter-university Consontium for Political and Social Research (P.O. Box 1248, Ann Arbor MI 48106; (313)
763-5010) is the major source for much social science empirical data, and thus it would surprise no one that in fact, in many of the datasets archived at the consortium, there are data on sexual attitudes and behaviors. The ICPSR collection is now accessible in a number of ways, by looking up a keyword in the annual ICPSR Guide To Resources Subject Index (on CDNet or printed from tape), or by searching RLIN, the Research Libraries Group's cataloging database. The 1989/90 subject index lists 38 studies under the keyword "Sexual," two studies under the keyword "Sexually," two more under the keyword "Homosexuality," and three under the keyword "Homosexuals." In addition, 11 studies are listed under "AIDS."

RLIN's MDF subfile (for machine-readable data files) is perhaps a better source since each ICPSR (and nonICPSR study) in the database is fully analyzed by subject, and one can productively search under the subjects AIDS, homosexuality, homosexuals, lesbians, sexual attitudes, rape, or sex offenders. The bulk of the sex data files listed in RLIN are bibliographic files from the WestLaw database concerning civil rights laws; however, dozens of ICPSR datasets also show up, most of those concerning sexual attitudes, and not behavior. Among recent datasets distributed by ICPSR on sexual behavior are the National Lesbian Health Care Survey, 1984-1985 (ICPSR Study 8991) and Dangerous Sex Offenders (ICPSR Study 8985); NORC's annual General Social Survey, distributed by ICPSR, also now includes questions on sexual behavior, and the 1988 General Social Survey was used in the recent analysis of the 1970 Kinsey Institute data (Fay et al, 1989).

ICPSR is also the site of the Midwest AIDS Biobehavioral Research Center, an NIH-funded project to collect survey questionnaires used in AIDS research. Thus far, some 5,000 questions have been collected, from over 40 surveys, in the hope of providing a database of questions so that some standardization and comparison studies will take place (Michael Traugott, personal communication, 25 May 1990).

A second major source of data is the Data Archive on Adolescent Pregnancy and Pregnancy Prevention (from Sociometrics Corporation, 170 State St., \#260, Los Altos CA 94022-2812; (415) 949-3832), now available in part on CD-ROM. Its 1990 Catalog of Products listed only six studies under the keyword "Sexual" and two other studies under keyword "Sexuality." However, a subject search of its database, under the topic "Sexuality," produced an 88-page printout, listing descriptions and variables for 28 studies. Among them: The 1983 Cuyahoga County, Ohio, Familial Communication and Adolescent Sexual Behavior Project, with 940 variables, including preteens and teens answering questions about homosexuality, masturbation, and oral sex (Study A1- 
A2). Another study focuses on sexual behavior of minority teens and preteens (Project Redirection, Study 91-94).

In addition, a new National Archive on Child Abuse and Neglect at Cornell University operated by its Family Life Development Center (E200 MVR Hall, Ithaca NY 14853-4401; (607) 255-7794), but physically located within the facilities of the Cornell Institute for Social and Economic Research, is a source for a growing number of data files on child sexual abuse. The archive is funded by a grant form the National Center on Child Abuse and Neglect.

A list of existing or proposed AIDS- or HIV-related data files appears as appendix B (four pages) in the U.S. Office of Science and Technology's 1988 report, $\underline{A}$ National Effort to Model AIDS Epidemiology. The principal investigators are identified, as are the cities or institutions where the data are based. Among the datasets named are AIDS Surveillance (Centers for Disease Control), NORC's General Social Survey, and an AIDS Behavioral Research Clearing House at Temple University.

With AIDS already having claimed the lives of more people in the United States than the number of Americans killed in the Vietnam War, a sense of urgency pervades recent calls for the establishment of a national AIDS or HIV database. The previously cited report from the Office of Science and Technology Policy, which advises the U.S. President, specifically called for the creation of a directory of relevant AIDS databases, support for access to significant local databases, and enhanced public access to national databanks. Researchers are unwilling to release data they themselves are still analyzing, and public-use AIDS case data is not released by city but rather only in terms of six larger geographical regions in the U.S. (see also Layne et al, 1988, 511). It also called for the creation and adoption of standards and guidelines for data collection, documentation and release.

In an appendix on long-term prospects for data management, the report argued against the concept that sharing of information implies the centralization of data. It elaborated as follows:

- Data from distinct sources are often not suitable for pooling because they werc not collected under similar circumstances.

- Data from different studies require different protection measures.

- Quality control is best exercised by the people who have the original responsibility and authority over the data contents and collection.

- Longitudinal studies require dynamic updating; remote compilations are unlikely to remain consistent.

- Flexibility to incorporate new data elements, as they appear to be useful, is difficult to achieve in central repositories dealing with many sources. - Technology and tradeoffs of systems versus personnel costs are moving computing toward distributed paradigms.

The report envisions a decentralized network-based hypertext-formatted information sharing system, best illustrated by this example of an end user sitting in front of a computer.

At the information mode, one may locate the title of a publication. Clicking on the title can produce the abstract, kept at that node. A click on the abstract can cause the text of the paper to be fetched, and the section titles of the paper will be displayed. Clicking a section name will obtain the corresponding section of the paper. Clicking a graph can produce the underlying values. A numerical result can be clicked on to show the algorithm or program used to obtain the result, from the workstation where the computation was performed. Clicking on another marker corresponding to the data will obtain the data, subject to privacy constraints, for display on the screen. Clicking a reference cited can continue this browsing process. Text so structured may also be annotated for further private of public use (p. 63).

Although the report did not call for the establishment of a national AIDS data center, contrary to a story in The Chronicle of Higher Education (Tumer, 1989), researchers involved in the report did separately call for such a center (Turner, 1989; Layne et al, 1988). As envisioned, such a center would house a national HIV database, "in its most complete form, a storehouse of raw data on HIV infection and the AIDS epidemic" (Layne et al, 1988, 512; see also Hirons et al, 1989). Proponents also propose that the database would furnish a standard agreement governing procedures on sharing raw data. They note that the creation of a national HIV database would require an "cxtraordinary level of commitment on the part of the research community. Individual researchers and institutions will have to share and protect large quantities of confidential data on the intimate behaviour of individuals. They will also have to share data that could otherwise be hoarded to build their own careers. But such a database is needed - and it is needed soon" (Layne et al, 1988, 512).

Supporters of the idea of a national center argue that the "current lack of a national AIDS data base center to collect, analyze and distribute the available data is a severe block to our understanding [of AIDS transmission]." As researchers who use mathematical models to understand the AIDS epidemic, they believe establishing a center "will encourage closer collaborations between modellers and data collectors" (Hyman and Stanley, 1987, VIII.3). 
Given the taboo concerning sex research, the United States, not surprisingly, appears to lag behind other countries in the area of data collection and access. The World Health Organization has been at the forefront of collecting global data on sexual practices, as part of a multinational study of AIDS (Booth, 1989). In addition to Geneva, where WHO is based, some of the data will be archived at Essex, England, at the ESRC [Economic and Social Research Council] Data Archive, where the coordinator of WHO's Homosexual Response Studies is situated (APM Coxon, personal communication, 27 May, 1990). Essex has also been the site of the computerized AIDS Register, which with funding from the Medical Research Council, lists ongoing research on AIDS.

In summary, improved data collection and access to sex data will only occur if sufficient funding, political support, public trust and researcher commitment all materialize. Otherwise, sex on the racks will more likely be found in some sex club, and not in a data archive.

\section{REFERENCES}

Associated Press, 1989. "Sullivan Orders Changes in Sex-Survey Questionnaire," The Orange County Register (8 April), A10.

Boffey, Philip M., 1987. "U.S. to Test for AIDS in 30 Cities; Household Sampling Put Off," The New York Times (3 December), 10.

Boodman, Sandra G., 1988a. "AIDS Study to Involve 800 D.C. Households: City Officials Say They Were Not Consulted on Federal Project," The Washington Post (28 July), A1, A18.

Boodman, Sandra G., 1988b. "Federal AIDS Study in D.C. Postponed: City Officials Say Household Survey Would Have Been Unfair," The Washington Post (29 July), A1, A12.

Booth, William, 1988. "The Long, Lost Survey on Sex," Science 239:4844 (4 March), 1084-1085.

Booth, William, 1989a. "Asking America About its Sex Life," Science 243:4889 (20 January), 304.

Booth, William, 1989b. "U.S. Probe Meets Resistance," Science 244:4903 (28 April), 419.

Booth, William, 1989c. "WHO Seeks Global Data on Sexual Practices," Science 244:4903 (28 April), 418-419.

Bull, Chris, 1987. "Feds Nab 150 in Pom Sting," Gay Community News (8-14 November), 1, 12.

Dannemeyer, William E., 1989. "Proposed 'Sex Survey"," Science 244:4912 (30 June), 1530. (Letter.)

Fay, Robert E. et al, 1989. "Prevalence and Patterns of Same- Gender Sexual Contact Among Men," Science 243:4889 (20 January), 338-348.
Forman, David, and Clair Chilvers, 1989. "Sexual Behaviour of Young and Middle Aged Men in England and Wales," British Medical Joumal 298 (29 April), 1137-1142.

Hayden, Tom, 1989. "“Magic Bullets' and Deadly Taboos: What We Don't Want to Know of Sexual Behavior May Kill Us," Los Angeles Times (7 June), II, 13.

Hirons, G. et al, 1989. "An Interactive Relational Database for HIV and the Immune System," in R. A. Morrisset, ed., Ye Conference Internationale sur Le SIDA: Le Defi Scientifique et Social: V Intermational Conference on AIDS: The Scientific and Social Challenge: Montreal, Quebec, Canada, June 4-9, 1989 (Ottawa, Ont.: International Development Research Centre), 652. (Abstract.)

Hyman, James M. and E. Ann Stanley, 1987. "Using Mathematical Models to Understand the AIDS Epidemic." Paper presented at the Los Alamos Center For Nonlinear Studies Conference on Nonlinearity in Biology and Medicine, May 18-22. Revised version in Mathematical Biosciences 90:1-2 (July/August 1988), 415-473.

Johansen, Bruce E., 1988. "The Meese Police on Porn Patrol," The Progressive (June), 20-21.

"Kinsey II," The Orange County Register (21 March 1989), B6. (Editorial.)

Klassen, Albert D., 1988. “"Lost' Sex Survey," Science 240:4851 (22 April), 375-376. (Letter.)

Layne, Scott P. et al, 1988. "The Need for National HIV Databases," Nature 333 (9 June), 511-512.

Lee, Kevin, 1987. "Sex Research or Law Enforcement?" NAMBLA Bulletin, " 8 (April/May), 3-4.

Money, John, 1990. "Sex: The Good, the Bad and the Kinky," Playboy (July), 46-49.

Peterson, Larry, 1989. "Dannemeyer Fights Proposed Sex Study," The Orange County Register (18 March), B1, B7.

Reinisch, June Machover, 1988. "Kinsey Sex Surveys," Science 240:4854 (13 May), 867. (Letter.)

Sonenschein, David, 1987. "On Having One's Research Seized," The Journal of Sex Research 23:3 (August),408414.

Specter, Michael, 1989. "Funds for Sex Survey Blocked by House Panel: AIDS Researchers Say Data is Essential," The Washington Post (26 July), A3.

Specter, Michael, 1990. "What's America Doing in 
Bed? We Need a National Sex Survey to Fight AlDS Effectively, So Why is Congress Ducking it?" The Washington Post (25 February), B1.

Stanley, Lawrence A., 1988. "The Child-Pornography Myth," Playboy (September), 41-44.

Stanley, Lawrence A., 1989. "The Child Porn Myth," Cardozo Arts \& Entertainment Law Journal 7:2, 295 358.

Tsang, Daniel C., 1987. "Moral Panic in North America: Implications for Sex Professionals." Paper presented at the Annual Conference of the Society for the Scientific Study of Sex, Western Region, 27-29 March, Beverly Hills, California.

Tsang, Daniel C., 1989. "Ethical Dilemmas in Sex Research and Therapy." Paper presented at the Annual Conference of the Society for the Scientific Study of Sex, Western Region, Marina Del Rey, California, 22-25 March.

Turner, Judith Axler, 1989. “Creation of \$6-Million National Center to Collect and Analyze Data on Spread of AIDS is Urged," The Chronicle of Higher Education (25 January), A4.

U.S. Office of Science and Technology Policy, 1988. A National Effort to Model AIDS Epidemiology. Washington, D.C.: Office of Science and Technology Policy.

Vobejda, Barbara, 1990. “'Unmarried Partner' Category to Provide First Census Data on Gay," The Washington Post (11 March). A6-A7.

Wolpert, Stuart, 1989. "Shaking Down the AIDS Data: People Don't Always Tell the Truth About Their Sexual Habits," UCLA Magazinę (Spring), 13-14.

Appendix A

Sample questionnaire from a U.S. Postal Inspection Service sting operation in the 1980s.

${ }^{1}$ Paper presented at the 16th Annual Conference of the International Association for Social Science Information Service and Technology (IASSIST), Poughkeepsie, New York, May 30-June 2, 1990. 
Appendix A

Sample questionnaire from a U.S. Postal Inspection Service sting operation in the 1980s.
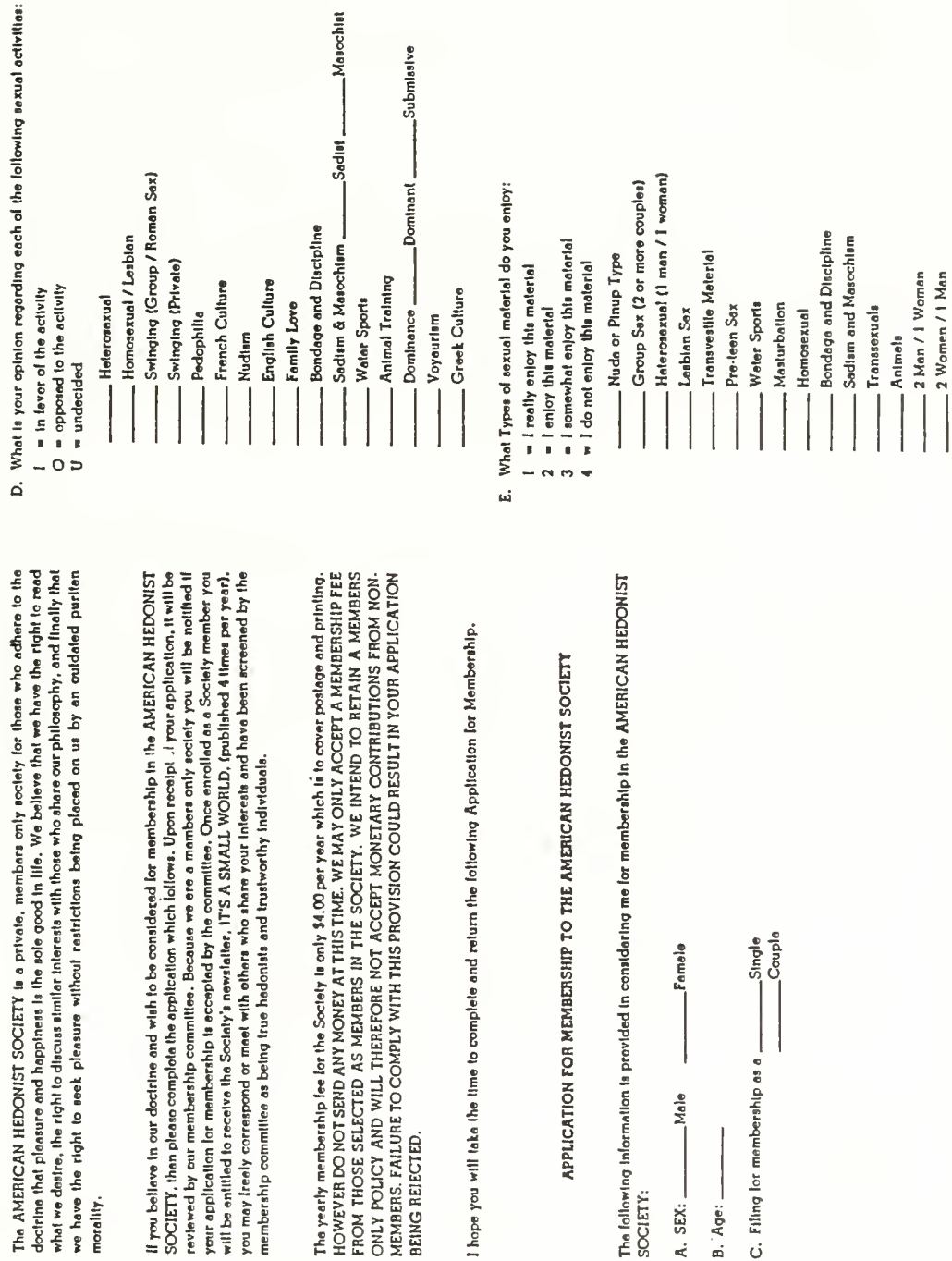


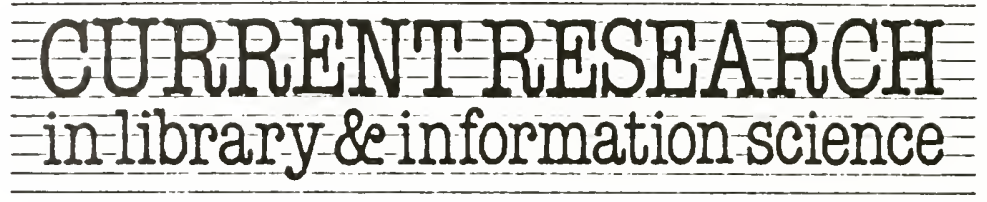

- CURRENT RESEARCH is an international quarterly journal offering a unique current awareness service on research and development work in library and information science, archives, documentation and the information aspects of other fields

- The journal provides information about a wide range of projects, from expert systems to local user surveys. FLA and doctoral theses, post-doctoral and research-staff work are included

- Each entry provides a complete overview of the project, the personnel involved, duration, funding, references, a brief description and a contact name. Full name and subject indexes are included

- Other features include a list of student theses and dissertations and a list of funding bodies. Each quarter, an area of research is highlighted in a short article

CURRENT RESEARCH is available on magnetic tape, as well as hard copy, and can be searched online on File 61 ( $S F=C R$ ) of DIALOG

Subscription: UK $\mathbb{1 8 6 . 0 0}$

Overseas (excluding N. America) £103.00

N. America US\$195.00

Write for a free specimen copy to

Sales Department

Library Association Publishing

7 Ridgmount Street

London WC1E TAE

Tel: $016367543 \times 360$

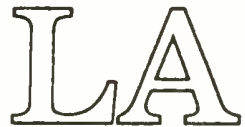




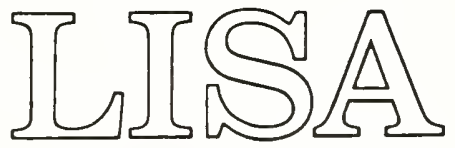

\section{Library \& Information Science Abstracts}

international scope and unrivalled coverage

LISA provides English-language abstracts of material in over thirty languages. Its serial coverage is unrivalled; 550 titles from 60 countries are regularly included and new titles are frequently added

- rapidly expanding service which keeps pace with developments

LISA is now available monthly to provide a faster-breaking service which keeps the user informed of the rapid changes in this field

- extensive range of non-serial works

including British Library Research and Development Department reports, conference proceedings and monographs

- wide subject span

from special collections and union catalogues to word processing and videotex, publishing and reprography

- full name and subject indexes provided in each issue abstracts are chain-indexed to facilitate highly specific subject searches

- available in magnetic tape, conventional hard-copy format, online (Dialog file 61) and now on CD-ROM

Twelve monthly issues and annual index

Subscription: UK $\mathbf{1 5 7 . 0 0}$

Overseas (excluding N. America) $£ 188.00$

N. America US $\$ 357.00$

Write for a free specimen copy to

Sales Department

Library Association Publishing

7 Ridgmount Sireet

London WCIE TAE

Tel: $016367543 \times 360$

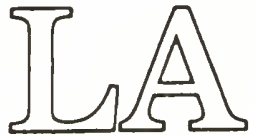

